\title{
Dyspnoea and flow-volume curve during exercise in COPD patients
}

\author{
A. Noseda*, J-P. Carpiaux*, J. Schmerber*, F. Valente**, J-C. Yernault***
}

Dyspnoea and flow-volume curve during exercise in COPD patients. A. Noseda, J-P. Carpiaux, J. Schmerber, F. Valente, J-C. Yernault. CERS Journals Ltd 1994.

ABSTRACT: The purpose of this study, in patients with chronic obstructive pulmonary disease (COPD), was to examine the relationship of dyspnoea, rated on a visual analogue scale (VAS), to 1) tidal ventilatory variables measured on exercise and 2) pre-exercise lung function.

Twenty one patients (forced expiratory volume in one second $\left(\mathrm{FEV}_{1}\right)$ mean (SD) $1.19(0.32) l$ ) were studied. During a preliminary test, the maximal workload was assessed and the upper end of the VAS was anchored. On the study day, the tidal flow-volume curve on exercise was monitored and dyspnoea was assessed serially every minute. In each individual, the relationship of dyspnoea to various tidal ventilatory variables was studied using linear regression analysis; results were reported as squared correlation coefficients, slopes and dyspnoea thresholds. Subsequently, the relationship of slopes and thresholds to pre-exercise lung function was examined.

In all patients, dyspnoea showed a close correlation with ventilation, tidal volume, breathing frequency and tidal flow. The tidal peak inspiratory flow was the best individual predictor of dyspnoea with a median $r^{2}$ of 0.91 . Patients with the poorest pre-exercise lung function exhibited the highest rates of increase in dyspnoea and the lowest thresholds, the strongest correlation being observed between the dyspnoea/ventilation slope and pre-exercise maximal peak inspiratory flow $\left(r^{2}\right.$ $=0.54)$.

In conclusion, for individual COPD patients dyspnoea on exercise is closely related to inspiratory flow. The degree of pre-exercise ventilatory impairment accounts, at most, for only half of the variation in dyspnoea perception between subjects.

Eur Respir J., 1994, 7, 279-285

\begin{abstract}
*Pulmonary Division, Dept of Internal Medicine, Hôpital Brugmann, Brussels, Belgium. **Medical Statistics Laboratory, Ecole de Santé Publique, Brussels, Belgium. ***Chest Dept, Hôpital Erasme, Université Libre de Bruxelles, Brussels, Belgium.
\end{abstract}

Correspondence: A. Noseda

Pulmonary Division

Hôpital Universitaire Brugmann

Place A. Van Gehuchten, 4

B-1020 Brussels

Belgium

Keywords: Dyspnoea

exercise test

obstructive lung diseases

visual analogue scale

Received: February 261993

Accepted after revision October 31993
The visual analogue scale (VAS) and the Borg scale are widely used tools for quantifying dyspnoea during exercise testing in patients with chronic obstructive pulmonary disease (COPD). The ability to predict the intensity of exercise-induced dyspnoea from mechanical variables is a controversial issue. Some investigators have produced multiple regression analyses relating dyspnoea in healthy subjects [1] or in respiratory patients $[2,3]$ to a variety of ventilatory variables, including pleural or mouth pressure, airflow, tidal volume, breathing frequency and duty cycle. On the other hand, Guz and co-workers showed that normal subjects $[4,5]$ and patients with COPD $[4,6]$ did not feel as breathless when voluntarily reproducing an increased ventilation as when the same ventilation was stimulated by $\mathrm{CO}_{2}$ inhalation or by exercise. This was despite tidal volume, breathing frequency [4, 6], airflow and pleural pressure [6] being very similar during voluntary or reflex hyperventilation. Similarly, in a study aimed to evaluate the influence of prior ventilatory experience on the estimation of breathlessness on exercise during either loaded or unloaded breathing, WILSON and JONES [7] reported that changes in the breathing pattern were not consistent with the changes in breathlessness.

In a previous study, we developed a procedure to assess dyspnoea on exercise in patients with COPD, using a VAS with its upper end anchored on a preliminary maximal exercise test [8]. We found that the rate of increase of dyspnoea with ventilation was unaffected by the subject's awareness of the progressive increase in work intensity, and showed good reproducibility after a two month interval. In the present study, we assessed dyspnoea and recorded the tidal flow-volume curve on exercise in a group of 21 patients with COPD. Our goal was to analyse dyspnoea in relation to various ventilatory variables in each individual, in an attempt to determine which tidal variable would show the closest correlation with the intensity of perceived dyspnoea. We also wanted to 
evaluate how much the variation in dyspnoea perception between subjects could be predicted by pre-exercise pulmonary function.

\section{Patients and methods}

\section{Patients}

Twenty three out-patients (18 males and 5 females) attending our Chest Clinic agreed to participate in a study of exercise-induced dyspnoea. Conditions for entry into the study were: 1) physician-diagnosed COPD; 2) airway obstruction with forced expiratory volume in one second $\left(\mathrm{FEV}_{1}\right)<70 \%$ predicted, $\mathrm{FEV}_{1} /$ forced vital capacity (FVC) $<65 \%$ and no increase in $\mathrm{FEV}_{1}$ exceeding $10 \%$ predicted after $200 \mu \mathrm{g}$ inhaled salbutamol; 3) selfreported breathlessness on exertion in everyday life; and 4) ability to perform cycle exercise.

Subjects with known systemic hypertension or heart disease, or with any peripheral leg disease interfering with cycle exercise, were not admitted.

The mean (SD) anthropometric features were: age 64 (9) yrs, height 169 (9) cm, and weight 70.0 (12.9) kg. Twenty subjects received a regular schedule of oral and/or inhaled bronchodilators; nine of the 23 also received inhaled steroids.

\section{Study design}

The study protocol was approved by the Ethics Committee of the Hôpital Brugmann, and all the patients gave informed consent. All subjects were naive to the purposes of the experiment. As we have described in a previous study [8], the upper end of the VAS was anchored in each subject on a preliminary test. On the next day (study day), cycle exercise was performed with measurement of ventilation and serial assessment of dyspnoea. On the study as well as on the preliminary day, the subjects attended the exercise laboratory in the afternoon and were asked to abstain from inhaled bronchodilators for at least $4 \mathrm{~h}$.

\section{Dynamic lung volumes and forced flow rates}

On the study day, maximal expiratory and inspiratory flow-volume curves were obtained at rest (subject sitting on the cycle) using a pneumotachograph (Jaeger, Wurzburg, Germany). At least three technically satisfactory manoeuvres were obtained. Volumes and flows were reported as raw data or as \% of predicted values, calculated from age and height [9].

\section{Visual analogue scale (VAS)}

A $20 \mathrm{~cm}$ horizontal VAS [10] was used to assess dyspnoea (D). A sliding scale linear potentiometer was attached to the ergometer handlebar. The lower end of the scale $(\mathrm{D}=0 \%)$ was described to the subject as "not breathless at all", whilst the feeling experienced by the subject on the preliminary test was used to define the upper end of the scale $(D=100 \%)$. On the study day, before exercising, the subject was requested to concentrate on breathlessness, and was instructed to move the slide to any point he/she wished, which best reflected the amount of perceived breathlessness, every time he/she would be asked to give a rating. Every minute, the subject was asked to rate breathlessness when $50 \mathrm{~s}$ had elapsed, and was allowed, during the subsequent $10 \mathrm{~s}$, to rectify the initial rating if he/she so wished. The slide was systematically returned to its baseline by the investigator, so that the subject was never reminded of his/her previous rating.

\section{Preliminary cycle test}

The procedure we used has been described in detail elsewhere [8]. Briefly, the subject exercised on an Elema cycle ergometer (Siemens, Erlangen, Germany) with unloaded pedalling during the first minute and a subsequent increase by $10 \mathrm{~W}$ every minute. The maximal workload (Wmax) was defined as the highest load reached and maintained for a full minute. At the very moment that the subject could no longer exercise and the load was set down to zero Watt, he/she was told by the investigator that the intensity of the perceived breathlessness at that moment was represented by the upper end of the VAS.

\section{Exercise protocol}

On the study day, we used a short high intensity protocol, with a load profile tailored on account of the subject's Wmax assessed at the preliminary test. After 3 min rest on the cycle, each subject exercised for $3 \mathrm{~min}$ at a low $(5,10$ or $15 \mathrm{~W})$ level (warm-up period). The subsequent 4 min period was a high intensity phase, the load being abruptly increased to such a value that a further increase by $10 \mathrm{~W}$ every minute allowed a peak load to be reached within $3 \mathrm{~min}$, which was maintained for the last minute. In subjects with $\mathrm{Wmax} \leq 80 \mathrm{~W}$, the peak load was set at Wmax $-5 \mathrm{~W}$, in those with Wmax $>80$ $\mathrm{W}$, the peak load was set at Wmax $-10 \mathrm{~W}$. Recovery included unloaded pedalling $(1 \mathrm{~min})$ followed by a $3 \mathrm{~min}$ rest period on the cycle. Thus, the subject breathed through the mouthpiece for $14 \mathrm{~min}$, and exercise duration was $8 \mathrm{~min}$.

\section{Recording of the flow-volume curve on exercise}

Ventilation, $\mathrm{O}_{2}$ consumption and $\mathrm{CO}_{2}$ production were assessed using an Ergopneumotest (Jaeger, Wurzburg, Germany). A specifically devised software (Medatec, Brussels, Belgium) was used to record the tidal flowvolume curve on exercise. Flow-time and volume-time curves were displayed on the computer screen during the test. The volume was reset at zero every time the flow 
passed through zero, to avoid any drift of the pneumotachograph. For each breath, the computer calculated the following: inspiratory duration $(\mathrm{TI})$, total breath duration (Ttot), breathing frequency $\left(f_{\mathrm{R}}\right)$, tidal volume $\left(\mathrm{VT}_{\mathrm{T}}\right)$, tidal peak inspiratory flow (PIFT) and tidal peak expiratory flow (PEFT). Every $10 \mathrm{~s}$, the last tidal flow-volume curve recorded during the elapsed $10 \mathrm{~s}$ period was displayed on the screen. Indices were sampled every $10 \mathrm{~s}$ as arithmetical means and, hence, were calculated on about three tidal cycles when $f_{R}$ was $15-20$ breaths $\cdot \mathrm{min}^{-1}$, and on about six cycles when $f \mathrm{R}$ was 30-40 breaths $\cdot \mathrm{min}^{-1}$. In addition, minute ventilation $\left(\dot{\mathrm{V}}_{\mathrm{E}}\right)$, mean inspiratory flow $\left(\mathrm{V}_{\mathrm{T}} / \mathrm{T}_{\mathrm{I}}\right)$ and fractional inspiratory duration (TI/Ttot) were calculated every $10 \mathrm{~s}$ from the means of $\mathrm{VT}_{\mathrm{T}} \mathrm{T} \mathrm{I}$ and, Ttot. Similarly, oxygen consumption $\left(\dot{\mathrm{V}}_{\mathrm{O}_{2}}\right)$ and $\mathrm{CO}_{2}$ production $\left(\dot{\mathrm{V}}_{2}\right)$ were sampled every $10 \mathrm{~s}$.

\section{Analysis}

Within-subject analysis. The relationship of dyspnoea to each variable during increasing intensity exercise was assessed on a within-subject basis by linear regression analysis (10 points included in each analysis). An individual example is shown in figure 1. The perception of exercise-induced dyspnoea was described in terms of strength of the relationship with any physiological variable (assessed as the squared correlation coefficient $\mathbf{r}^{2}$ ), rate of increase (slope) and dyspnoea threshold (x axis intercept). Ventilatory variables were subsequently ranked by decreasing $\mathrm{r}^{2}$ values. The regression analysis was also performed on PIFT (or PEFT) values recorded on exercise divided by the PIF (or PEF) value measured on the maximal flow-forced vital capacity curve at rest. The latter approach is further designated as the study of the relationship of dyspnoea to PIF (or PEF) tidal to maximal ratio, as opposed to raw data.

Between-subject analysis. The relationship between the slopes and thresholds characterizing dyspnoea perception on exercise and lung function data measured at rest was assessed by linear regression analysis, using a Bonferroni correction to allow for multiple comparisons $(\mathrm{p}<0.01$ as threshold of significance).
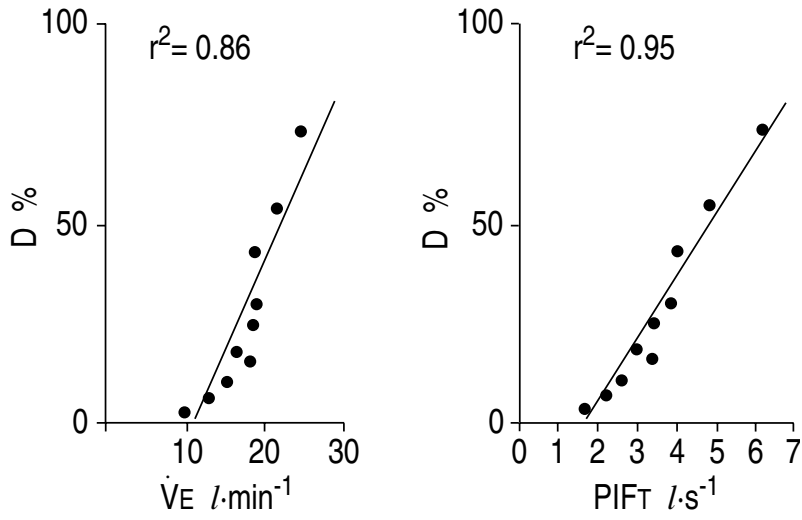

Fig. 1. - Individual example of dyspnoea ratings (D\%) on exercise plotted against corresponding values of ventilation and tidal peak inspiratory flow. (PIFT).

\section{Results}

Use of the visual analogue scale

Two subjects used the scale as an on-off instrument, with either 0 or $100 \%$ as sole ratings, and were excluded from further analysis.

\section{Preliminary test}

In the group of 21 subjects using the VAS correctly, Wmax assessed on the preliminary test varied between $50(\mathrm{n}=1), 60 \quad(\mathrm{n}=2), 70 \quad(\mathrm{n}=2), 80 \quad(\mathrm{n}=1), 90 \quad(\mathrm{n}=4), 100$ $(n=1), 110(n=4), 120(n=2), 130(n=2)$ and $140(n=2)$ W.

\section{Spirometry}

The results are shown in table 1 and are consistent with severe obstructive ventilatory defect.

\section{Intensity of dyspnoea}

Twelve subjects were not breathless at all at rest $(\mathrm{D}=0 \%)$ whilst the other nine perceived some degree of

Table 1. - Pre-exercise dynamic volumes and maximal flows in 21 patients with chronic obstructive pulmonary disease

\begin{tabular}{|c|c|c|c|}
\hline & $\begin{array}{l}\text { Whole group } \\
\qquad n=21\end{array}$ & $\begin{array}{c}\text { Patients breathless } \\
\text { at rest } \\
n=9\end{array}$ & $\begin{array}{c}\text { Patients not breathless } \\
\text { at rest } \\
\mathrm{n}=12\end{array}$ \\
\hline $\mathrm{FEV}_{1} l$ & $1.19(0.32)$ & $1.09 \quad(0.36)$ & $1.26(0.28)$ \\
\hline$\%$ pred & 45 (12) & 42 (11) & 47 (13) \\
\hline FVC $l$ & $2.58 \quad(0.60)$ & $2.53(0.51)$ & $2.62(0.69)$ \\
\hline$\%$ pred & 76 (12) & $78 \quad(7)$ & 74 (15) \\
\hline $\mathrm{FEV}_{1} / \mathrm{FVC} \%$ & $47 \quad(11)$ & 44 (11) & 49 (10) \\
\hline PEF $l \cdot \mathrm{s}^{-1}$ & 3.54 (1.15) & 3.06 (1.44) & $3.93(0.66)$ \\
\hline$\%$ pred & 49 (16) & 43 (17) & 54 (13) \\
\hline PIF $l \cdot \mathrm{s}^{-1}$ & $3.99 \quad(1.47)$ & $3.61 \quad(1.89)$ & $4.30 \quad(1.00)$ \\
\hline
\end{tabular}

Data are presented as mean and SD in parenthesis. $\mathrm{FEV}_{1}$ : forced expiratory volume in one second; FVC: forced vital capacity; PEF: peak expiratory flow; PIF: peak inspiratory flow. 


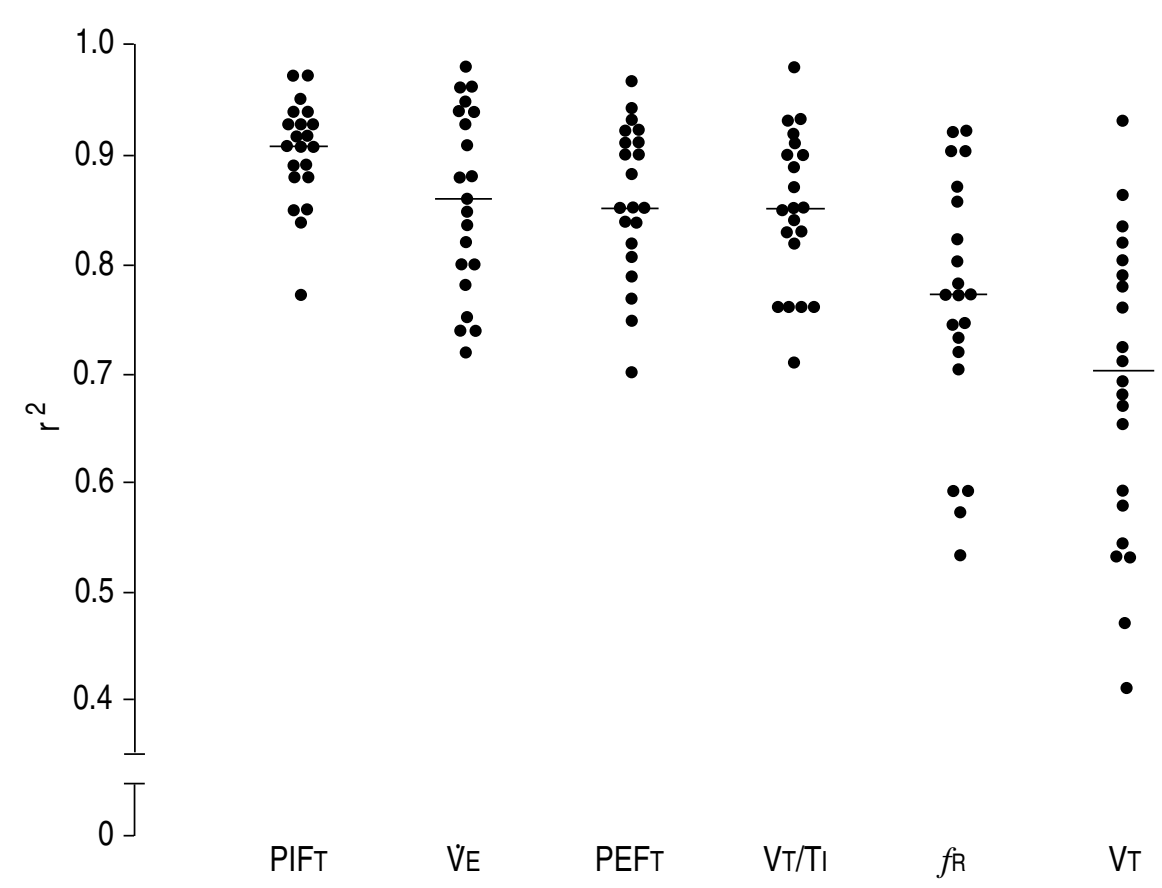

Fig. 2. - Individual values for $\mathrm{r}^{2}$ (squared correlation coefficient) in a within-subject linear regression analysis of dyspnoea on exercise against ventilatory variables in 21 subjects with chronic obstructive pulmonary disease (COPD). Bars indicate median values. Ventilatory variables are ranked by decreasing strength of correlation. PIFT: tidal peak inspiratory flow; VE: minute ventilation; PEFT: tidal peak expiratory flow; VT/TI: mean inspiratory flow; $f_{\mathrm{R}}$ : breathing frequency; $\mathrm{VT}_{\mathrm{T}}$ tidal volume.

dyspnoea, varying from $1.5-13.5 \%$ of line length. Dynamic lung volumes and forced flow rates were slightly lower in the breathless at rest subgroup (table 1), but the differences did not reach significance (Student's t-test for unpaired samples, $\mathrm{p}>0.05$ ). Maximal dyspnoea, as rated after exercising at the peak load, was (mean (SD)) 76(18)\% of line length. Four out of 21 subjects rated the intensity of maximal dyspnoea as $100 \%$.

\section{Relationship of dyspnoea to ventilatory variables (with- in-subject analysis)}

A significant positive relationship was found in all subjects between dyspnoea ratings and all the variables studied, except for Ti/Ttot. The scatter of individual $\mathrm{r}^{2}$ values, taken as a measurement of the strength of the correlation, is shown in figure 2 for the relationship of dyspnoea to ventilatory variables. We found that PIFT had the first rank, with a median $\mathrm{r}^{2}$ of 0.91. Dyspnoea was also closely related to $\dot{\mathrm{V}}_{2}$ and $\dot{\mathrm{V}}_{\mathrm{CO}_{2}}$ (median $\mathrm{r}^{2}$, respectively, 0.76 and 0.86 ), but showed no consistent correlation with $\mathrm{TI} / \mathrm{Ttot}$ statistical significance was achieved in only five subjects who exhibited a negative relationship. The correlation between dyspnoea and $f_{\mathrm{R}}$ was stronger than that with $V_{T}$ in 13 subjects, but weaker in eight; that between dyspnoea and $\mathrm{VT}_{\mathrm{T}}$ TI was stronger than that with $\mathrm{T}_{\mathrm{I}} / \mathrm{Ttot}$ in all subjects. When the three flow indices (VT/TI, PIFT, PEFT) were compared, the strongest relationship involved PIFT in $16, \mathrm{VT}_{\mathrm{T}} \mathrm{T}_{\mathrm{I}}$ in three and PEFT in two subjects. Slopes and thresholds obtained from linear regression analysis of dyspnoea ratings against ventilatory variables are presented in table 2 . The between-subject range in slope
Table 2. - Dyspnoea versus ventilatory variables on exercise: within-subject linear regression analysis in 21 subjects with chronic obstructive pulmonary disease

\begin{tabular}{lcllcl}
\hline & \multicolumn{3}{c}{ Slope } & \multicolumn{2}{c}{ Threshold } \\
\hline$\dot{\mathrm{V}}_{\mathrm{E}}$ & 3.53 & $(2.29)$ & $\% \cdot l^{-1} \mathrm{~min}$ & 13.6 & $(4.1) l \cdot \mathrm{min}^{-1}$ \\
$f_{\mathrm{R}}$ & 6.56 & $(3.25)$ & $\% \cdot \mathrm{min}$ & 18.4 & $(4.1) \mathrm{min}^{-1}$ \\
$\mathrm{VT}_{\mathrm{T}}$ & 95.3 & $(63.1)$ & $\% \cdot l^{-1}$ & 0.66 & $(0.23) l$ \\
$\mathrm{VT}_{\mathrm{T}} \mathrm{T}$ & 71.1 & $(46.5)$ & $\% \cdot l^{-1} \cdot \mathrm{s}$ & 0.57 & $(0.18) l \cdot \mathrm{s}^{-1}$ \\
$\mathrm{PIFT}$ & 31.1 & $(17.5)$ & $\% \cdot l^{-1} \cdot \mathrm{s}$ & 1.30 & $(0.54) l \cdot \mathrm{s}^{-1}$ \\
PEFT & 35.6 & $(23.2)$ & $\% \cdot l^{-1} \cdot \mathrm{s}$ & 1.05 & $(0.41) l \cdot \mathrm{s}^{-1}$ \\
\hline
\end{tabular}

Data are presented as mean and SD in parenthesis. $\dot{V}_{E}$ : minute ventilation; $f \mathrm{R}$ : breathing frequency; VT: tidal volume; $\mathrm{VT} / \mathrm{T}$ : mean inspiratory flow; PIFT: tidal peak inspiratory flow; PEFT: tidal peak expiratory flow.

(coefficient of variation (CV) 11-14\%) was larger than that in either $\mathrm{r}^{2}(\mathrm{CV} 1-5 \%)$ or in threshold $(\mathrm{CV}$ $2-6 \%)$.

\section{Relationship of dyspnoea perception to lung function} (between-subject analysis)

The relationship between the slopes and thresholds characterizing the perception of dyspnoea in relation to either $\dot{\mathrm{V}}_{\mathrm{E}}, \mathrm{VT}, \mathrm{VT} / \mathrm{T}$, PIFT or PEFT and lung function data was studied. The main finding was that dynamic lung volumes and maximal flows exhibited a tendency to negative relationship with slopes and positive relationship with thresholds. Variables showing a significant relationship are indicated in tables 3 and 4 . When using PIF to assess the degree of functional impairment 
at rest, significance was achieved in the majority of correlations studied. PEF was similarly quite well correlated, but spirometric measurements showed few if any correlations. Among the parameters characterizing dyspnoea perception, the dyspnoea slopes (table 3) yielded a larger number of significant relationships than thres-

Table 3. - Relationship between rates of increase in dyspnoea (D) and pre-exercise lung function in 21 patients with chronic obstructive pulmonary disease

\begin{tabular}{llcccl}
\hline & $\mathrm{FEV}_{1}$ & FVC & $\mathrm{FEV}_{1} / \mathrm{FVC}$ & PEF & PIF \\
\hline D/VE slope & $0.43^{*}$ & 0.12 & 0.29 & $0.52^{* *}$ & $0.54^{* *}$ \\
D/VT slope & 0.22 & 0.10 & 0.12 & 0.27 & $0.31^{*}$ \\
D/VT/Ti slope & 0.16 & 0.12 & 0.06 & $0.32^{*}$ & $0.48^{* *}$ \\
D/PIFT slope & 0.13 & 0.17 & 0.01 & $0.35^{*}$ & $0.47^{* *}$ \\
D/PEFT slope & 0.30 & 0.22 & 0.07 & $0.48^{* *}$ & $0.48^{* *}$ \\
\hline
\end{tabular}

Values reported in the table are squared correlation coefficients $\left(r^{2}\right)$ for linear regression analysis of slope (raw data) against lung function index (raw data). *: significance at $\mathrm{p}<0.01$ level; **: significance at $\mathrm{p}<0.001$ level. For abbreviations see legends to tables 1 and 2 .

Table 4. - Relationship between dyspnoea thresholds and pre-exercise lung function in 21 patients with chronic obstructive pulmonary disease

\begin{tabular}{lccccl}
\hline & FEV $_{1}$ & FVC & FEV $_{1} /$ FVC & PEF & PIF \\
\hline VE threshold & 0.11 & 0.14 & 0.01 & 0.17 & $0.31^{*}$ \\
VT threshold & 0.18 & 0.29 & 0.00 & 0.16 & $0.34^{*}$ \\
VT/TI threshold & 0.11 & 0.13 & 0.01 & 0.11 & 0.21 \\
PIFT threshold & 0.00 & $0.31^{*}$ & 0.03 & 0.13 & 0.20 \\
PEFT threshold & 0.29 & $0.40^{*}$ & 0.00 & $0.31^{*}$ & $0.33^{*}$
\end{tabular}

Values reported in the table are squared correlation coefficients $\left(\mathrm{r}^{2}\right)$ for linear regression analysis of threshold (raw data) against lung function index (raw data). *: significance at $\mathrm{p}<0.01$ level. For abbreviations see legends to tables 1 and 2.

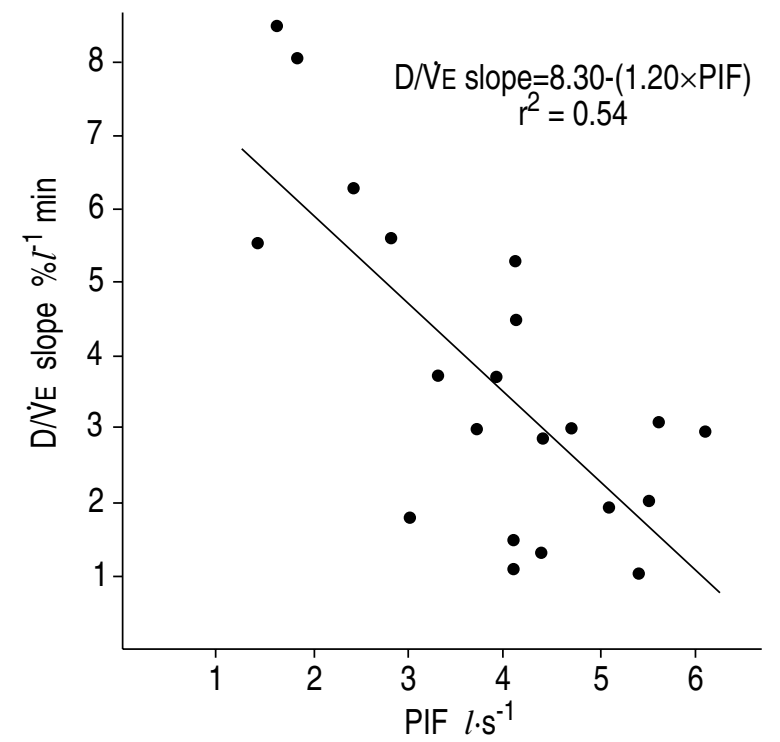

Fig. 3. - Relationship between the rate of increase in dyspnoea with increasing ventilation on exercise and pre-exercise maximal peak inspiratory flow in 21 patients with COPD. For abbreviations see legend to figure 2 . holds (table 4$)$. The strongest correlation $\left(r^{2}=0.54\right)$ was obtained between pre-exercise maximal PIF and the $\mathrm{D} / \dot{\mathrm{V}}_{\mathrm{E}}$ slope, and is illustrated in figure 3. Expressing lung function data as \% predicted and/or using slopes and thresholds derived from the analysis of dyspnoea against PIF (PEF) tidal to maximal ratio resulted in slightly weaker correlations than those obtained when using the raw data.

\section{Relationship of dyspnoea perception to ventilatory response to exercise (between-subject analysis)}

$\dot{\mathrm{V}} \mathrm{E}$ and $\dot{\mathrm{V}}_{\mathrm{CO}_{2}}$ on exercise showed a very close relationship, with a median $\mathrm{r}^{2}$ of 0.96 . The $\dot{\mathrm{V}} / \dot{\mathrm{V}}_{\mathrm{CO}_{2}}$ slope (mean, (SD)), reflecting the ventilatory response to exercise, was $35.6(5.0) l \cdot l^{-1} \mathrm{CO}_{2}$. No significant relationship was found between the $\mathrm{D} / \dot{\mathrm{V}}_{\mathrm{E}}$ slope and the $\dot{\mathrm{V}}_{\mathrm{E}} / \dot{\mathrm{V}}_{\mathrm{CO}_{2}}$ slope.

\section{Discussion}

In the present study, we have evaluated the relationship between exercise-induced dyspnoea, rated on a VAS, and various ventilatory variables in a group of 21 patients with COPD. Dyspnoea showed a close relationship with most tidal variables studied; the tidal peak inspiratory flow on exercise showing the strongest correlation. Dyspnoea thresholds were low, close to the ventilatory conditions at rest. Patients with the most severe spirometric impairment at rest were found to have the highest rates of increase in dyspnoea and the lowest thresholds. In this evaluation, PIF recorded on the maximal inspiratory flow-volume curve at rest was the most useful index, but with a low predictive value for any individual slope or threshold.

As the methods used to assess and to analyse dyspnoea strongly influence the results obtained, our study design needs a critical evaluation. We chose to define the sensation being studied simply as "breathlessness". We felt that it was unnecessary to define it further, since the experience is unique to the individual and, therefore, cannot be adequately described by another person [11]. We used a VAS and anchored its upper end on a preliminary maximal exercise test, as described previously [8]. On the study day, we used a single burst of high intensity exercise, which has the advantage of short duration and may avoid plateauing artefacts in dyspnoea ratings as shown previously [8]. We set the peak level of high intensity exercise 5-10 W lower than the subject's Wmax, to take into account the possible detrimental effect of the mouthpiece on work performance [12]. In agreement with most groups, we selected ventilation as the a priori best known stimulus for dyspnoea on exercise [4]. We attempted to further characterize ventilation in terms of its basic tidal volume, frequency and flow components, and we analysed the relationship between dyspnoea rated on the VAS and ventilatory variables by linear regression analysis, a widely used method for this purpose [13-15]. 
In the present study, we found a close relationship between dyspnoea and ventilation in all subjects. These results are in agreement with previous findings in subjects with COPD by several groups using a VAS [8, 14] or a Borg scale [14, 16, 17], with mean $r$ values ranging from 0.94-0.97 across studies. Concern has been expressed about the possibility that the linear D/VE relationship could be enhanced by the subject's expectation of an increase in dyspnoea parallel to the progressive increase in work intensity [14]. However, we have previously shown that the slope relationship between dyspnoea and ventilation is unaltered, when using a nonprogressive high intensity load profile [8]. When $f_{\mathrm{R}}$ and $\mathrm{V}_{\mathrm{T}}$ were considered, dyspnoea had a significant positive relationship with both factors, but the correlations were weaker than that with $\dot{V}_{E}$ and neither of the two was consistently more strongly related to dyspnoea. In contrast, when VE was analysed as $\mathrm{VT}_{\mathrm{T}} / \mathrm{T}_{\mathrm{I}} \times \mathrm{T}_{\mathrm{I}} / \mathrm{Ttot}$, the correlation was maintained (at a similar strength as with $\dot{\mathrm{V}}_{\mathrm{E}}$ ) for $\mathrm{V}_{\mathrm{T}} / \mathrm{T}_{\mathrm{I}}$, whilst a negative relationship between dyspnoea and TI/Ttot was significant in only a small minority of subjects. In other words, flow was identified as the relevant factor of ventilation in its relationship with dyspnoea. A further analysis of flows revealed that the PIFT had the closest correlation with dyspnoea.

In this study, pre-exercise peak maximal flows showed a positive relationship with dyspnoea thresholds, and a negative one with rates of increase in dyspnoea. These results agree with a theoretical expectation that threshold should be lowered and slope increased as the impedance of the respiratory system increases [1]. In a retrospective study of 18 subjects with COPD limited during exercise by dyspnoea, RAMPULLA et al. [17] found a negative relationship between $\mathrm{FEV}_{1}$ and the $\mathrm{D} / \mathrm{VE}$ slope (dyspnoea assessed on a Borg scale and $\dot{V}_{E}$ normalized for the maximal voluntary ventilation (MVV) estimated as $35 \times\left(\mathrm{FEV}_{1}\right)$. We had a similar result in our previous study involving 19 patients with COPD [8]. In the present study, we found that pre-exercise maximal PIF showed the strongest correlation with thresholds and rates of increase in dyspnoea on exercise across subjects. This finding, parallel to the first rank of the tidal PIF among the correlates of dyspnoea on a within-subject basis, is consistent both with the fact that dyspnoea in patients with airway obstruction is predominantly an inspiratory sensation [18], and that PIF depends on inspiratory muscle effort [19]. However, even the correlations with PIF were too modest to be able to predict the dyspnoea slope or threshold of a given individual. It has been suggested [20] that expressing PIFT as a fraction of the subject's pre-exercise maximal PIF might enhance its correlation with dyspnoea (as this mode of expression takes into account the subject's reserve and, therefore, reflects inspiratory effort) but we were unable to confirm this hypothesis.

In the early sixties, CAMPBELl and Howell [21] formulated the "length-tension inappropriateness" theory of respiratory sensation, suggesting a primary role for respiratory muscle afferents in mediating dyspnoea. In this setting, studies involving either healthy subjects [1] or patients with cardiopulmonary disorders [2] were designed by the Hamilton group, with the specific purpose of demonstrating that exercise-induced dyspnoea represents the perception of respiratory muscle effort. The results showed that a multiple regression incorporating four or five independent variables, including pleural pressure, inspiratory flow rate, $\mathrm{T}_{\mathrm{I}} / \mathrm{Ttot}$ and $\mathrm{f}_{\mathrm{R}}[1]$, or the same with the addition of $\mathrm{V}_{\mathrm{T}} / \mathrm{VC}$ [2], could predict exercise-induced dyspnoea assessed on a Borg scale. The $r^{2}$ in both of these studies was only 0.69 . In the present study, evaluating the relationship of dyspnoea rated on a VAS to ventilation or flow in each individual and, subsequently, correlating perceptual parameters with pre-exercise lung function, we found the latter accounted for, at most, 54\% of the variation in dyspnoea perception between subjects. Limitations in predicting dyspnoea intensity from mechanical variables reflect the complexity of the sensation, which must not be confused with perception of respiratory effort, from which dyspnoea is clearly dissociated in some circumstances [22, 23].

Finally, we found no correlation between the rate of increase in dyspnoea with ventilation and the ventilatory response to exercise. Several conditions have been shown to alter separately the $\mathrm{D} / \dot{\mathrm{V}} \mathrm{E}$ and the $\dot{\mathrm{V}} / \dot{\mathrm{V}}_{\mathrm{CO}_{2}}$ slopes. Acute oral morphine ingestion in COPD patients reduces the $\mathrm{D} / \dot{\mathrm{V}}_{\mathrm{E}}$ slope without affecting the $\dot{\mathrm{V}} / \dot{\mathrm{V}}_{\mathrm{CO}_{2}}$ slope [24] whilst in patients with chronic hyperthyroïdism the $\dot{\mathrm{V}} / \dot{\mathrm{V}}_{\mathrm{CO}_{2}}$ slope is increased and the $\mathrm{D} / \dot{\mathrm{V}} \mathrm{E}$ slope is normal [25]. The absence of correlation between the two slopes in the present study is consistent with these findings, and provides further evidence that dyspnoea experienced by patients with COPD is a sensation quite different from a simple awareness of an increase in ventilation $[7,26]$.

Acknowledgements: The authors thank M. Telerman for his support and F. Martinez for secretarial assistance.

\section{References}

1. El-Manshawi A, Killian KJ, Summers E, Jones NL. Breathlessness during exercise with and without resistive loading. J Appl Physiol 1986; 61: 896-905.

2. Leblanc P, Bowie DM, Summers E, Jones NL, Killian KJ. Breathlessness and exercise in patients with cardiorespiratory disease. Am Rev Respir Dis 1986; 133: 21-25.

3. Mahler DA, Faryniarz K, Lentine T, Ward J, Olmstead M, O'Connor GT. Measurement of breathlessness during exercise in asthmatics. Predictor variables, reliability and responsiveness. Am Rev Respir Dis 1991; 144: 39-44.

4. Adams L, Lane R, Shea A, Cockcroft A, Guz A. Breathlessness during different forms of ventilatory stimulation: a study of mechanisms in normal subjects and respiratory patients. Clin Sci 1985; 69: 663-672.

5. Lane R, Cockcroft A, Guz A. Voluntary isocapnic hyperventilation and breathlessness during exercise in normal subjects. Clin Sci 1987; 73: 519-523.

6. Freedman S, Lane R, Guz A. Breathlessness and respiratory mechanics during reflex or voluntary hyperventilation in patients with chronic airflow limitation. Clin Sci 1987; 73: 311-318. 
7. Wilson RC, Jones PW. Influence of prior ventilatory experience on the estimation of breathlessness during exercise. Clin Sci 1990; 78: 149-153.

8. Noseda A, Carpiaux JP, Schmerber J, Yernault JC. Dyspnoea assessed by visual analogue scale in patients with chronic obstructive pulmonary disease during progressive and high intensity exercise. Thorax 1992; 47: 363-368.

9. Quanjer $\mathrm{PhH}$, ed. Standardized lung function testing. Bull Eur Physiopathol Respir 1983; 19 (Suppl. 5).

10. Stark RD, Gambles A, Lewis JA. Methods to assess breathlessness in healthy subjects: a critical evaluation and application to analyse the acute effects of diazepam and promethazine on breathlessness induced by exercise or by exposure to raised levels of carbon dioxide. Clin Sci 1981; 61: 429-439.

11. Mahler DA. The measurement of dyspnoea during exercise in patients with lung disease. Chest 1992; 101: 242S-247S.

12. Beaumont A, Cockroft A, Guz A. A self-paced treadmill walking test for breathless patients. Thorax 1985; 40: 459-464.

13. Wilson RC, Jones PW. A comparison of the visual analogue scale and modified Borg scale for the measurement of dyspnoea during exercise. Clin Sci 1989; 76: 277-282.

14. Muza SR, Silverman MT, Gilmore GC, Hellerstein HK, Kelsen SG. Comparison of scales used to quantitate the sense of effort to breathe in patients with chronic obstructive pulmonary disease. Am Rev Respir Dis 1990; 141: 909-913.

15. Mador MJ, Kufel TJ. Reproducibility of visual analog scale measurements of dyspnea in patients with chronic obstructive pulmonary disease. Am Rev Respir Dis 1992; 146: 82-87.
16. Silverman M, Barry J, Hellerstein H, Janos J, Kelsen S. Variability of the perceived sense of effort in breathing during exercise in patients with chronic obstructive pulmonary disease. Am Rev Respir Dis 1988; 137: 206-209.

17. Rampulla C, Baiocchi S, Dacosto E, Ambrosino N. Dyspnea on exercise. Pathophysiologic mechanisms. Chest 1992; 101: 248S-252S.

18. Morris MJ. Asthma-expiratory dyspnoea? $\mathrm{Br}$ Med $\mathrm{J}$ 1981; 283: 838-839.

19. Hyatt RE, Flath RE. Relationship of air flow to pressure during maximal respiratory effort in man. $J$ Appl Physiol 1966; 21: 477-482.

20. Killian KJ. The objective measurement of breathlessness. Chest 1985; 88: 84S-90S.

21. Campbell EJM, Howell JBL. The sensation of breathlessness. Br Med Bull 1963; 19: 36-40.

22. Simon PM, Schwartzstein RM, Weiss JW, et al. Distinguishable sensations of breathlessness induced in normal volunteers. Am Rev Respir Dis 1989; 140: 1021-1027.

23. Demediuk BH, Manning H, Lilly J, et al. Dissociation between dyspnoea and respiratory effort. Am Rev Respir Dis 1992; 146: 1222-1225.

24. Light RW, Muro JR, Sato RI, Stansbury DW, Fischer CE, Brown SE. Effects of oral morphine on breathlessness and exercise tolerance in patients with chronic obstructive pulmonary disease. Am Rev Respir Dis 1989; 139: 126-133.

25. Small D, Gibbons W, Levy RD, de Lucas P, Gregory W, Cosio MG. Exertional dyspnea and ventilation in hyperthyroïdism. Chest 1992; 101: 1268-1273.

26. O'Neill PA, Stark RD, Allen SC, Stretton TB. The relationship between breathlessness and ventilation during steady-state exercise. Bull Eur Physiopathol Respir 1986; 22: 247-250. 